University of Nebraska - Lincoln

DigitalCommons@University of Nebraska - Lincoln

Faculty Papers and Publications in Animal

Science

Animal Science Department

January 1993

\title{
Estimates of Variances Due to Direct and Maternal Effects for Growth Traits of Romanov Sheep
}

G. A. Maria
Spain

K. G. Boldman

DeKalb Poultry Research, Inc.

L. Dale Van Vleck

University of Nebraska-Lincoln, dvan-vleck1@unl.edu

Follow this and additional works at: https://digitalcommons.unl.edu/animalscifacpub

Part of the Animal Sciences Commons

Maria, G. A.; Boldman, K. G.; and Van Vleck, L. Dale, "Estimates of Variances Due to Direct and Maternal Effects for Growth Traits of Romanov Sheep" (1993). Faculty Papers and Publications in Animal Science. 251.

https://digitalcommons.unl.edu/animalscifacpub/251

This Article is brought to you for free and open access by the Animal Science Department at DigitalCommons@University of Nebraska - Lincoln. It has been accepted for inclusion in Faculty Papers and Publications in Animal Science by an authorized administrator of DigitalCommons@University of Nebraska - Lincoln. 


\title{
Estimates of Variances Due to Direct and Maternal Effects for Growth Traits of Romanov Sheep ${ }^{1,2}$
}

\author{
G. A. María ${ }^{3}$, K. G. Boldman ${ }^{4}$, and L. D. Van Vleck \\ Department of Animal Science, University of Nebraska, Lincoln, 68583-0908 \\ and Roman L. Hruska U.S. Meat Animal Research Center, ARS, USDA, \\ Clay Center, NE 68933-0166
}

\begin{abstract}
Records of growth traits of 2,086 Romanov lambs were used to estimate variance components for an animal model and genetic correlations between growth traits. Traits analyzed were birth weight (BWT), weaning weight (WW), 90-d weight (W90), and daily gain for the periods birth to weaning (DG1) and weaning to $90 \mathrm{~d}$ (DG2). Weaning was at approximately $40 \mathrm{~d}$. Variance components were estimated using restricted maximum likelihood with an animal model including fixed effects for year $\times$ season, sex, rearing type, and litter size and random effects for the direct genetic effect of the animal (with relative variance $\mathrm{h}^{2}$ ), the maternal genetic effect (with relative variance $\mathrm{m}^{2}$ ), the permanent environmental effect ( $w i t h$ relative variance $c^{2}$ ), and random residual effect. Genetic correlations were
\end{abstract}

estimated for a model with the same fixed effects and only additive genetic effects. Estimates of the variances of random effects, $h^{2}, \mathrm{~m}^{2}$, and $\mathrm{c}^{2}$, respectively, as a proportion of phenotypic variance were $.04, .22, .10$ (BWT); .34, .25, .0 (WW); .09, .01, .07 (W90); .26, $.17, .02$ (DG1); and .15, .01, .03 (DG2). Estimates of genetic correlations were .12 (BWT with WW); .24 (BWT with W90); .48 (WW with W90); .69 (DG1 with DG2); -.01 (BWT with DG1); .05 (BWT with DG2); .59 (WW with DG1); .47 (WW with DG2);.67 (W90 with DG1); and .98 (W90 with DG2). Results suggest that selection should be effective for WW, DG1, and DG2 but less effective for BWT and W90. An important maternal effect was observed for BWT, WW, and DG1. The estimates of genetic correlations showed no genetic antagonisms among the traits.

Key Words: Sheep, Romanov, Spain, Growth Traits, Variance Components

J. Anim. Sci. 1993, 71:845-849

\section{Introduction}

Lambing rate and milk production are important components of an efficient market lamb production system, as are growth potential and carcass characteristics. Ways to increase meat output in the system are to increase the number of lambs produced per ewe and to improve growth performance of the lambs. The first objective can be reached by increasing lambing

\footnotetext{
${ }^{1}$ Published as paper no. 9981, Journal Ser., Nebraska Agric. Res. Div., Univ, of Nebraska, Lincoln 68583-0908.

${ }^{2}$ Appreciation is extended to K. Meyer for the DFREML and REMLPK programs. The authors gratefully acknowledge C. Pieramati for his help in the data editing and to D. Gabiña and I. Sierra for their useful comments. This study was supported by a grant from "Ministerio de Educación y Ciencia," Spain.

${ }^{3}$ Present address: Anim. Prod. Dept., Faculty of Veterinary, University of Zaragoza, Miguel Servet 177, (50013) Zaragoza, Spain.

${ }^{4}$ Present address: DeKalb Poultry Research, Inc., 3100 Sycamore Road, DeKalb, IL 60115.

Received June 8, 1992.

Accepted November 9, 1992.
}

rate and lambing frequency, whereas the second requires improvement in growth potential and survival of lambs. To enhance lambing rate, crossbreeding with hyperprolific breeds (e.g., Romanov, Finnsheep) has been used in Spain and other countries. The advantage provided by crossbreeding over purebred schemes has been estimated by Valls (1983) to be $40 \%$. In Spain, the Romanov breed has performed better than Finnsheep (Valls, 1983). The Romanov breed was imported to Spain in 1973 and has been extensively used as a sire breed in crossbreeding systems with local ewes (Sierra, 1979; Valls et al., 1984; Leite et al., 1989). Two composite breeds (Salz and Mariné strains) have been created in Spain using local ewes and Romanov sires (Sierra, 1985). One reason not to use Romanov in crossbreeding schemes for meat production systems is the poor performance for growth and carcass traits traditionally attributed to this breed (Ricordeau et al., 1990). Nevertheless, most of the studies of Romanov sheep have focused on reproductive traits.

To take advantage of different schemes for breed utilization, the genetic parameters for the traits of 
importance should be known (Boujenane and Bradford, 1991). The objective of this study was to estimate variances and covariances due to direct and maternal genetic effects and permanent maternal environmental effects for growth traits using an animal model with data from purebred Romanov lambs.

\section{Materials and Methods}

Data for this study were obtained from the Romanov nucleus of OVHI S.A. farm at Talavera de la Reina (Spain). Live weight at birth (BWT), weaning (WW), and $90 \mathrm{~d}$ (W90) and ADG for the periods birth to weaning (DG1) and weaning to $90 \mathrm{~d}$ (DG2) of 2,086 lambs born from 1987 to March 1990 were available. Natural (single-sire groups, SG) and artificial insemination (AI) were used with lambing seasons centered in February (1,001 lambs), June (563 lambs), and October (522 lambs). Because of the low fertility of ewes in spring, October lambing resulted from hormone-induced matings. Lambs were progeny of 15 sires (used in various year-seasons) and 352 dams. Sires and dams were mated at random.

Weaker lambs in excess of two per ewe (433 lambs) were moved from natural rearing (NR) to artificial rearing ( $\mathbf{A R}$ ) with milk replacer and pelleted feed. After approximately $2 \mathrm{~d}$ in an individual lambing pen, ewe and lambs were moved to larger rearing pens with other ewes and their lambs until weaning at approximately $40 \mathrm{~d}$ of age. High-quality feed was supplied to lambs from $15 \mathrm{~d}$ of age to the end of the fattening period (approximately $100 \mathrm{~d}$ ). Ewes were fed at a late gestation level from $5 \mathrm{wk}$ before lambing to lambing and were fed a lactating diet from lambing to weaning. During the dry period a maintenance level was used (ARC, 1980).

The DFREML programs of Meyer (1988, 1989) modified for use with SPARSPAK (Boldman and Van Vleck, 1991) were used for the variance component analyses for individual traits. Derivative-free restricted maximum likelihood (DFREML) was described by Smith and Graser (1986) and Meyer (1989). The SPARSPAK package (George et al., 1980) was used to reorder the mixed-model equations once and then the iteratively updated equations were repeatedly solved by Cholesky factorization to calculate the likelihood.

The general representation of the animal model used is as follows:

$$
\mathbf{y}=\mathbf{X b}+\mathbf{Z}_{\mathbf{a}} \mathbf{a}+\mathbf{Z}_{\mathrm{m}} \mathbf{m}+\mathbf{Z}_{\mathrm{c}} \mathbf{c}+\mathbf{e}
$$

where $\mathbf{y}$ is a $\mathbf{N} \times 1$ vector of records, $\mathbf{b}$ denotes the fixed effects in the model with association matrix $\mathbf{X}, \mathbf{a}$ is the vector of direct genetic effects with association matrix $\mathbf{Z}_{\mathbf{a}}, \mathbf{m}$ is the vector of maternal genetic effects with association matrix $\mathbf{Z}_{\mathrm{m}}$, $\mathbf{c}$ is the vector of permanent maternal environmental effects with association matrix $\mathbf{Z}_{\mathfrak{c}}$, and $\mathbf{e}$ denotes the vector of residual (temporary environmental) effects. Fixed effects included in the model were year $\times$ season $(10)$, sex (2), litter size (6), and rearing type (2). The variance-covariance structure for the model is as follows:

$$
\mathbf{V}\left[\begin{array}{c}
\mathbf{a} \\
\mathbf{m} \\
\mathbf{c} \\
\mathbf{e}
\end{array}\right]=\left[\begin{array}{cccc}
\mathbf{A} \sigma_{\mathrm{a}}^{2} & \mathbf{A} \sigma_{\mathrm{am}} & 0 & 0 \\
\mathbf{A} \sigma_{\mathrm{am}} & \mathbf{A} \sigma_{\mathrm{m}}^{2} & 0 & 0 \\
0 & 0 & \mathbf{I}_{\mathrm{c}} \sigma_{\mathrm{c}}^{2} & 0 \\
0 & 0 & 0 & \mathbf{I}_{\mathrm{n}} \sigma_{\mathrm{e}}^{2}
\end{array}\right]
$$

where $\mathbf{A}$ is the numerator relationship matrix, $I_{c}$ is an identity matrix with order number of ewes, and $I_{n}$ is an identity matrix with order number of records.

Genetic correlations were calculated using the multiple-trait REMLPK program (Meyer, 1985), which accounts for only one random factor, additive genetic effects, in the model. Fixed effects were year $\times$ season, sex, litter size, and rearing type.

\section{Results and Discussion}

In the sample analyzed, $50.4 \%$ of the lambs were male and $49.6 \%$ female. Lambs from natural rearing represented $50.2 \%$ of the sample, and $49.8 \%$ were from artificial rearing. The distribution by lambing season was $48.1 \%$ (February), 27.3\% (June), and $24.6 \%$ (October). Single lambs represented $4 \%$ of the sample, $38.9 \%$ were twins, $47.1 \%$ were triplets, and the remaining were from litters of four or more lambs.

Live weights and ADG are summarized in Table 1. Live weights and daily gains were similar to those observed for Romanov lambs and slightly less than those for the Aragonesa breed or $F_{1}$ (Aragonesa $\times$ Romanov) lambs (Ricordeau et al., 1982; Sierra, 1983; Valls et al., 1984). Coefficients of variation for live weights ranged from $14 \%$ for WW and W90 to $25 \%$ for BWT. For ADG, CV were $17 \%$ for DG1 and $15 \%$ for DG2. Differences in BWT were large between single and twin lambs but not between triplets and more.

Results of variance component analyses are presented in Tables 2 and 3. Relative variance due to direct genetic effects $\left(h^{2}\right)$ for BWT was .04 with relative variance due to maternal genetic effects $\left(\mathrm{m}^{2}\right)$ of .22. Variance due to permanent environmental effects $\left(c^{2}\right)$, coded as an effect of the dam (possibly due to uterine capacity, feeding level at late gestation, and maternal behavior of the ewe), was .10 of the total variance. The analysis of weaning weight results in a direct heritability estimate of .34 and a maternal heritability estimate of .25 . In this case no variance due to permanent environmental effects was detected 
Table 1. Means, standard deviations, and coefficients of variation for live weight at birth (BWT), weaning (WW), and 90 days (W90) and average daily gain from birth to weaning (DG1) and weaning to 90 days (DG2) ${ }^{\mathrm{a}}$

\begin{tabular}{lccc}
\hline \hline Trait & $\overline{\mathrm{x}}$ & SD & CV, \% \\
\hline BWT & 2.46 & .63 & 25 \\
WW & 14.07 & 1.95 & 14 \\
W90 & 22.50 & 3.14 & 14 \\
DG1 & 220 & 41 & 17 \\
DG2 & 232 & 34 & 15 \\
\hline
\end{tabular}

${ }^{a}$ Live weight in kilograms; daily gain in grams per day.

$\left(c^{2}=0\right)$. Live weight at $90 \mathrm{~d}$ had a low maternal heritability (.01), a direct heritability of .09 , and $c^{2}$ of .07. A possible interpretation of differences on $c^{2}$ between WW and W90 could be that suckling lambs are still dependent on mothers, whereas weaned lambs depend on themselves; furthermore, the influence of the non-permanent environmental factors becomes more important after weaning.

Except for the low heritability estimates for BWT, which reflect a large maternal effect, the other estimates fall within the range of values reported in the literature. Heritability estimates for live weights were larger than those observed by Khaldi and Boichard (1989) for Barbary lambs, whose estimates of $\mathrm{h}^{2}$ were .02 (BWT), .04 (WW), and .03 (W90). Waldron et al. (1990) reported heritability estimates for BWT, WW, and W90 in crossbred lambs (Suffolk, Dorset, and Rambouillet) of .13, .09, and .24, respectively. Mavrogenis et al. (1980), working with Chios sheep, obtained estimates of $\mathrm{h}^{2}$ for the same traits to be $.13, .12$, and .17 , respectively. The estimate of $h^{2}$ for WW is similar to that observed by Martin et al. (1980) for crossbred lambs (containing Finnsheep, E. Friesian, Border Leicester, and Dorset Horn genes). Nevertheless, for BWT and W90, there were discrepancies between our estimates of $h^{2}$ and those of

Table 2. Estimates ${ }^{a}$ from variance component analyses for live weight at birth (BWT), weaning (WW), and 90 days (W90)

and average daily gain from birth to weaning (DG1) and weaning to 90 days (DG2)

\begin{tabular}{lcccc}
\hline \hline Trait & $\sigma^{2}$ & $\mathrm{~h}^{2}$ & $\mathrm{~m}^{2}$ & $\mathrm{c}^{2}$ \\
\hline BWT & .40 & .04 & .22 & .10 \\
WW & 3.79 & .34 & .25 & .00 \\
W90 & 9.84 & .09 & .01 & .07 \\
DG1 & 1.72 & .26 & .17 & .02 \\
DG2 & 1.15 & .15 & .01 & .03 \\
\hline \multicolumn{2}{c}{${ }^{2} \sigma^{2}=$ phenotypic variance, $\mathrm{h}^{2}=$ heritability (direct effect), $\mathrm{m}^{2}=$} \\
maternal heritability, $\mathrm{c}^{2}=$ relative variance due to permanent en- \\
vironmental effect of dam.
\end{tabular}

Martin et al. (1980), who reported estimates of $h^{2}$ to be .22 for both traits. Boujenane and Kerfal (1990) found estimates of heritability for live weights in D'man lambs to be .34 (BWT), .23 (WW), and .52 (W90). Reports of $\mathrm{m}^{2}$ estimates for economically important sheep traits are scarce. In general, our estimates of $\mathrm{m}^{2}$ for live weights were higher than those reported in the literature (Khaldi and Boichard, 1989).

For ADG, heritability estimates for direct genetic effect were .26 (DG1) and .15 (DG2), similar to those observed by Barillet et al. (1982) for Lacaune lambs, by Mavrogenis et al. (1980) for Chios lambs, and by Bouix et al. (1982) for $F_{1}$ Romanov $\times$ Berrichon and Romanov $\times$ Ile de France lambs; however, these values were higher than those reported by Khaldi and Boichard (1989) in Barbary sheep and by Boujenane and Kerfal (1990) in D'man lambs.

Estimates of $h^{2}$ for DG1 were also larger than those by Waldron et al. (1980) in crosses of Suffolk, Dorset, and Rambouillet, by Mavrogenis et al. (1980) for Chios lambs, and by Boujenane and Kerfal (1990) for D'man lambs, who reported estimates of $.07, .12$, and .12 , respectively.

Maternal heritability was important only for DG1 (.17), whereas estimates for DG2 were small (.01). Our estimates of $\mathrm{m}^{2}$ for DG1 were significantly higher than those by Khaldi and Boichard (1989), who reported estimates of maternal heritability ranging from .02 to .06 for growth traits in Barbary sheep. In the data reported by these authors maternal heritability tended to increase with the age of the lamb. Relative variances due to permanent environmental effects were small for the two daily gains considered, ranging from .02 for DG1 to .03 for DG2.

High estimates of correlation between direct and maternal effects (Table 3 ) were observed for both live weights and daily gains $(\geq .97)$, which is probably due to the small amount of data and to the structure of this data set (i.e., the number of generations for which animals were measured both directly and as dams was limited). This is a common pattern that occurs with

Table 3. Estimates of environmental variance $\left\langle\sigma_{\mathrm{e}}^{2}\right\rangle$, additive variance $\left(\sigma_{\mathrm{a}}^{2}+1 / 2 \sigma_{\mathrm{m}}^{2}\right)$, and genetic correlation between animal effects $\left(\sigma_{\mathrm{am}}\right)$ for live weight at birth (BWT), weaning (WW), and 90 days (W90) and average daily gain from birth to weaning (DG1) and weaning to 90 days (DG2)

\begin{tabular}{lccr}
\hline \hline Trait & $\sigma_{\mathrm{e}}^{2}$ & $\sigma_{\mathrm{a}}^{2}+1 / 2 \sigma_{\mathrm{m}}^{2}$ & $\sigma_{\mathrm{am}}$ \\
\hline BWT & .29 & .016 & -.99 \\
WW & 2.64 & 1.371 & -.98 \\
W90 & 8.20 & 1.222 & -.97 \\
DG1 & 1.32 & .460 & -.99 \\
DG2 & .93 & .187 & .99 \\
\hline
\end{tabular}


Table 4. Genetic correlations (above the diagonal) and phenotypic correlations

(below the diagonal) among birth weight (BWT), weaning weight (WW),

90-day weight (W90), and average daily gain from birth to weaning (DG1) and from weaning to 90 days (DG2). Heritability estimates are on the diagonala,b

\begin{tabular}{lccccc}
\hline \hline & BW & WW & W90 & DG1 & DG2 \\
\hline BWT & .07 & .12 & .24 & -.01 & .05 \\
& $(.01)$ & $(.03)$ & $(.02)$ & $(.03)$ & $(.03)$ \\
WW & -.58 & .58 & .48 & .59 & .47 \\
& $(.30)$ & $(.05)$ & $(.02)$ & $(.02)$ & $(.02)$ \\
W90 & -.29 & .43 & .11 & .67 & .98 \\
& $(.44)$ & $(.28)$ & $.02)$ & .32 & $(.00)$ \\
DG1 & -.37 & .79 & .80 & $(.03)$ & .69 \\
& $(.36)$ & $.12)$ & $.14)$ & .81 & $(.01)$ \\
DG2 & -.42 & $(.25)$ & $(.01)$ & $.13)$ & $(.02)$ \\
& $(.39)$ & & .99 & $(39)$ \\
\hline
\end{tabular}

aEstimates using REMLPK multiple trait programs (Meyer, 1985) and fitting model 1 (variance components estimated: $\sigma_{\mathrm{a}}^{2}, \sigma_{\mathrm{e}}^{2}$ ).

${ }^{\text {b }}$ Small numbers between parentheses are lower bound standard errors from REMLPK.

many small data sets, and even with some that are not small. Boldman et al. (1991) obtained estimates of $r_{a m}$ for 200-d weight of .97 and .89 for Red Poll and Brown Swiss cattle, respectively. Shi et al. (1992) also found high negative estimates of $r_{a m}$ working with Limousin field data, and Eler et al. (1992) reported estimates of $r_{a m}$ on 205-d and 365-d weights in Nelore cattle of $\geq-.91$. There is a lack of information about $r_{\text {am }}$ estimates in sheep. Khaldi and Boichard reported estimates for growth traits in Barbary lambs of $\leq-.62$. The problem mentioned above may also be due to a flat likelihood with the data and structure, so that rounding errors in likelihood mean that distinguishing between different estimates is impossible.

It should be remembered that the extremely high values of $r_{a m}$ are biologically impossible. However, after restarting the program with different starting values, it still converges to the same estimates. In light of this it can be deduced that the other parameters are not greatly affected. In spite of this fact, we have to be cautious with the estimates obtained in this study, and probably it would be necessary to check them again with larger data sets. The difficulty is that large sheep data sets are scarce in Spain and there is a lack of studies on variance components analysis performed with local field data, which are essential to implement the local breeding programs.

Additive by additive and dominance effects (e.g., Model 6 in Meyer, 1988) need further investigation. In this study, and due to the sparsity of the $\mathbf{D}$ matrix, it was not possible to check these aspects. The importance of nonadditive genetic sources of variance (dominance and epistatic variance) for reproductive and production traits in sheep is as yet unclear. Results of crossbreeding experiments (Ricordeau et al., 1990) emphasize the importance of dominance and epistatic effects, but estimates of variance components analysis within populations are still rare and the results conflicting.

Genetic and phenotypic correlations among growth traits are presented in Table 4 . The genetic correlation between BWT and WW was .12; that between BWT and W90 was .24. The largest genetic correlation among live weights was between WW and W90 (.48). The DG1 and DG2 had a genetic correlation of .69. However, BWT had small genetic correlations with DG1 and DG2 (-.01 and .05). Genetic correlations for WW with DG1 and DG2 were .59 and .47.

Table 4 shows estimates from a multiple-trait analysis for heritability of growth traits fitting a model with direct genetic effects as the only random factor (Meyer, 1985, 1986). The estimates were .07, .58 , and .11 for BWT, WW, and W90, respectively, and .32 and .14 for DG1 and DG2, respectively. In general, heritability estimates were smaller with the singletrait, full model than with the multiple-trait, additive direct effects model, especially for weaning weight (.34 vs .58) and for DG1 (.26 vs .32).

\section{Implications}

Selection could be effective for weaning weight but less effective for birth weight or 90-d weight. Selection for average daily gain could be more effective for birth to weaning than for weaning to $90 \mathrm{~d}$. The maternal genetic component was important for the weight of the lamb at birth and at weaning, whereas variation in 90-d weight seemed not to depend much on maternal genetic effects. Genetic correlations among growth traits of Romanov lambs were, in general, positive, indicating that selection for any of the traits should 
result in genetic improvement in the other traits. Permanent environmental effects seem to have influence on birth weight but not on weaning or 90-d weights.

\section{Literature Cited}

ARC. 1980. The Nutrient Requirement of Ruminant Livestock. p 351 Agric. Research Council, CAB, Slough, U.K.

Barillet, F., Bibe, B., and J. Bouix. 1982. Genetics parameters of growth $0-150 \mathrm{~d}$ within two standardized breeding environments for Lacaune sheep. Proc. 2nd World Congr. Gent. Appl Livest. Prod. VIII:712.

Boldman, K. G., and L. D. Van Vleck. 1991. Derivative-free restricted maximum likelihood estimation in animal models with a sparse matrix solver. J. Dairy Sci. 74:4337.

Boldman, K. G., L. D. Van Vleck, K. E. Gregory, and L. V. Cundiff 1991. Estimates of direct and maternal parameters for $200 \mathrm{~d}$ weight in purebred and composite lines of beef cattle. J. Anim. Sci. 69(Suppl. 1):203 (Abstr.).

Boujenane, I., and G. E. Bradford. 1991. Genetic effects on ewe productivity of crossing D'man and Sardi breeds of sheep. J. Anim. Sci. 69:525.

Boujenane, I., and M. Kerfal. 1990. Estimates of genetic and phenotypic parameters for growth traits of D'man lambs. Anim. Prod. $51: 173$

Bouix, J., B. Bibe, and C. Lefebre. 1982. Genetic parameters of growth and carcass quality for meat-sheep in progeny testing station. Proc. 2nd World Congr. Gent. Appl. Livest. Prod. VIII. 732.

Eler, J. P., J.B.S. Ferraz, R. B. Lobo, and L. A. Josakian. 1992. Genetic antagonism between growth and maternal ability in Nelore cattle. J. Anim. Sci. 70(Suppl. 1):138 (Abstr.).

George, A., J. Liu, and E. Ng. 1980. User guide for SPARSPAK: Waterloo sparse linear equation package. CS-78-30, Dept. of Computer Sci., Univ, of Waterloo, ON, Canada.

Khaldi, G., and D. Boichard. 1989. Direct and maternal effect on the growth characters in the barbary sheep breed. Ann. Inst. National Recherche Agronomique Tunisie 62(2):3.

Leite, A., J. Silva, and F. Calheiros. 1989. Increase of meat production by increasing prolificacy. Productive results on raising Merino Branco and $F_{1}$ Romanov $\times$ Merino $B$ ewes. Symp. Santarem, 23-25 September 1987, Portugal. In: J. C. Flamant and P. Morand Fher (Ed.) Evaluation des ovins et des caprins Méditerranéens. pp 415-427. Rapport CEE. EUR. 11893.

Martin, T. G., D. I. Sales, C. Smith, and D. Nicholson. 1980. Phenotypic and genetic parameters for lamb weights in a synthetic line of sheep. Anim. Prod. 30:261.
Mavrogenis, A. P., A. Louca, and O. W. Robison. 1980. Estimates of genetic parameters for pre-weaning and post-weaning growth traits of Chios lambs. Anim. Prod. 30:271.

Meyer, K. 1985. Maximum likelihood estimation of variance components for a multivariate mixed model with equal design matrices. Biometrics 41:153.

Meyer, K. 1986. Restricted maximum likelihood to estimate genetic parameters-in practice. Proc. 3rd World Congr. Genet. Appl. Livest. Prod., Lincoln, NE, 12:454.

Meyer, K. 1988. DFREML, a set of programs to estimate variance components under an individual animal model. J. Dairy Sci. 69(Suppl. 2):33

Meyer, K. 1989. Restricted maximum likelihood to estimate variance components for animal models with several random effects using a derivative-free algorithm. Genet. Sel. Evol. 21:317.

Ricordeau, G., J. Thimonier, J. P. Poivei, M. A. Driancourt, M. T. Hochereau-de-Reviers, and L. Tchamitchian. 1990. I.N.R.A. Research on the Romanov Sheep Breed in France: A review. Livest. Prod. Sci. 24:305.

Ricordeau, G., J. Razungles, L. Tchamitchian, G. Lefevre, and J. C. Brunel. 1982. Paramètres phénotypiques et génétiques des caractères de croissance et de reproduction des brebis croisées Berrichon du Cher $\times$ Romanov $\mathrm{F}_{1}$ à $\mathrm{F}_{4}$. Ann. Genet. Sel. Anim. $14: 327$.

Shi, M. J., D. Laloe, F. Menissier, and G. Renand. 1992. Estimation of genetic and environmental parameters of pre-weaning growth and conformation in the french Limousin field data. Proc. 43rd Annu. Mtg. EAAP 1:222 (Abstr.).

Sierra, I. 1979. Mejora de los caracteres reproductivos de la Raza Aragonesa por cruzamiento con la Romanov. Zootechnia XXVII (1-2-3):9

Sierra, I. 1983. Growth rate and other parameters in lambs: effect of genotype, sex, type of birth and lambing season. Ann. Facultad Veterinaria 18-19:461.

Sierra, I. 1985. La raza sintética Salz. ONE Monografías, Ovino, Barcelona, Spain.

Smith, S. P., and H.-U. Graser. 1986. Estimating variance components in a class of mixed models by restricted maximum likelihood. J. Dairy Sci. 69:1156.

Valls, M. 1983. Frequent lambing of sheep flocks in Spain: productivity and management consequences. Livest. Prod. Sci. 10:49.

Valls, M., M. Espejo, F. Colomer, and M. López. 1984. El cruzamiento de las razas Finesa y Romanov con la Rasa Aragonesa. I. Obtención y características de los corderos $\mathrm{F}_{1}$ en comparación con los rasos. Anal. INIA Ser. Ganadera 18:25.

Waldron, D. F., D. L. Thomas, J. M. Stookey, T. G. Nash, F. K. McKeith, and R. L. Fernando. 1990. Central ram tests in the Midwestern United States: III. Relationship between sire's central test performance and progeny performance. J. Anim. Sci. 68:45. 